\title{
The Influence of Window-Wall Ratio on Heating Energy Consumption of Rural House in Severe Cold Regions of China
}

\author{
Teng Shao ${ }^{1}$, Hong $\mathrm{Jin}^{2}$, Wuxing Zheng ${ }^{1}$ and Jin Wang ${ }^{1}$ \\ ${ }^{1}$ School of Mechanics, Civil Engineering and Architecture, Northwestern Polytechnical University, Xi'an, 710072, China \\ ${ }^{2}$ School of Architecture, Harbin Institute of Technology, Harbin, 150006, China
}

\begin{abstract}
Rural houses in severe cold areas of China are mostly single-storey independent buildings with large shape coefficient. Compared with urban residential, it has larger contact area between envelope and outdoor environment of each household. Meanwhile, the heat transfer coefficient of window is usually greater than that of external wall and roof. The window-wall ratio is one of the important indicators affecting the energy consumption of rural house. This paper takes window-wall ratio as the main variable, building orientation, thermal performance of envelope and window heat transfer coefficient as the auxiliary variables, and applies DesignBuilder software to quantitatively analyse the mechanism of window-wall ratio on rural house's heating energy consumption under the interactive influence of multiple factors. Results show that the influence rule of window-wall ratio with different orientations on heating energy consumption will change when the thermal performance of envelope or window heat transfer coefficient changed. The synthetic effect of various factors should be considered in the design to reasonably determine the windowwall ratio of rural house.
\end{abstract}

\section{Introduction}

Under the background of vigorously promoting green building [1], the study of building low-energy design is of great significance. The rural houses' area of China accounts for more than $50 \%$ of total building area, and its energy consumption is higher than that of urban residential. According to the $<$ China's research report on building energy consumption (2017)>, rural houses consumed 197 million tons of standard coal in 2015, accounting for $22.9 \%$ of the total building energy consumption. In the design stage, adopting reasonable energy-saving design measures has greater energy saving potential. Rural houses in severe cold areas are mostly single-storey independent buildings with large shape coefficient. Compared with urban residential, it has larger contact area between envelope and outdoor environment of each household. Window-wall ratio is one of the important indicators affecting energy consumption, and the dissipation ratio is as high as $20 \%$ $40 \%$ [2]. Its influence on heating energy consumption has both advantages and disadvantages. On the one hand, it can obtain more sunlight and improve indoor thermal environment in winter. On the other hand, the heat transfer coefficient of window is usually greater than that of external wall and roof, the larger the window area, the greater the heating energy consumption. It is necessary to explore the influence rule of window-wall ratio on heating energy consumption in accordance with performance requirements and climatic conditions, so as to guide architects to determine the window-wall ratio reasonably in design stage.

At present, the scholars have carried out many studies on the impact of window-wall ratio on building energy consumption in residential buildings [3-11], but most of them are based on specific climatic conditions and lack of comprehensive consideration of different parameters. Window-wall ratio design is usually carried out after the plane function is determined, while different building orientation, thermal performance of envelope and window heat transfer coefficient often require different window-wall ratio design strategies to meet the energy saving needs. This paper, taking rural house of severe cold regions in China as example, selects window-wall ratio as the main variable, building orientation, thermal performance of envelope and window heat transfer coefficient as the auxiliary variables, and applies DesignBuilder software to quantitatively analyze the mechanism of window-wall area ratio on rural house's energy consumption under the interactive influence of multiple factors.

\section{Research methods}

\subsection{Baseline model}

Considering the construction age, building layout, space scale, envelope structure etc., a baseline model was created based on the survey results of rural housing in severe cold areas, which is the single-story detached 
building. The building area is $70.06 \mathrm{~m} 2$, with $11.3 \mathrm{~m}$ length and $6.2 \mathrm{~m}$ width, and the indoor net height is $2.6 \mathrm{~m}$. The interior space is divided into entrance, bedroom, kitchen and storeroom. The floor plan and section of baseline model is shown in Fig.1.

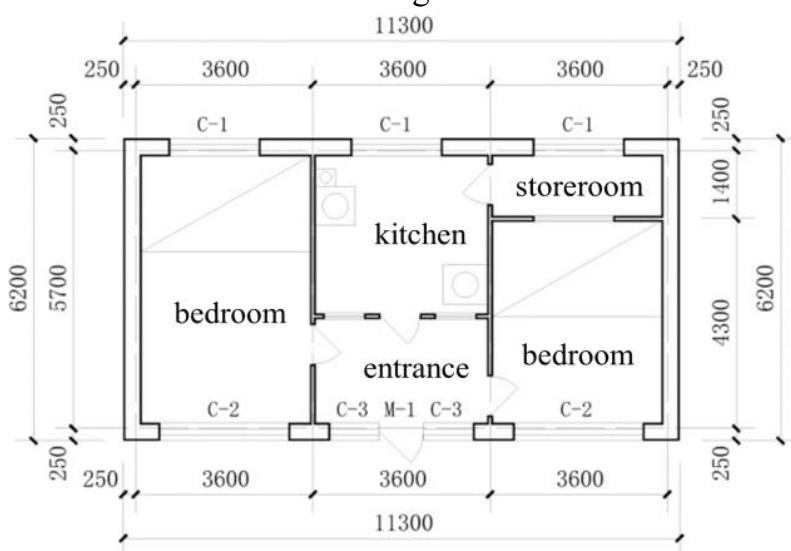

(a) Plan

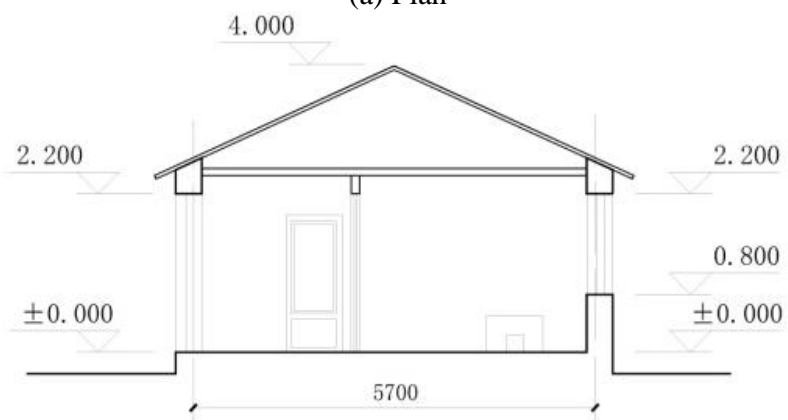

(b) Section

Fig. 1. The schematic view of rural house's baseline model.

\subsection{Simulation software and parameters setting}

The DesignBuilder software is used to calculate the heating energy consumption, which passed the building envelope thermal performance and energy consumption testing [12]. In the simulation, the interior space division is not considered, and the whole building is defined as a single zone. Parameters are implemented according to China standards and survey results for inputs. The Chinese standard weather data of Harbin, a representative city of severe cold regions, is used for outdoor calculation parameters. Indoor temperature and air change rate are set as $14{ }^{\circ} \mathrm{C}$ and $0.5 \mathrm{~h}^{-1}[13]$. The heating time in this area is October 20 to the next year April 12. The operating time of heating equipment is from $06: 00$ to $22: 00$, the utilization rate is $100 \%$ and from 22:00 to $06: 00$, the utilization rate is $50 \%$. The indoor personnel density is 0.04 people $/ \mathrm{m}^{2}$, the human metabolism rate and average thermal resistance of clothing in winter are 0.9 met and 1.4 clo respectively. The opening time of lamps is from 6:00 to 8:00 and $17: 00$ to $22: 00$, and the lighting power density is set at $4.0 \mathrm{~W} / \mathrm{m}^{2}$, ignoring the heat dissipation of other nonheating equipment.

\subsection{Variables setting}

Window-wall ratio as the main variable, seven values are set from 0.2 to 0.8 , with a step size of 0.1 . Three auxiliary variables, namely, building orientation, external window heat transfer coefficient and thermal performance of envelope, therein four values are set for building orientation: east, west, south and north; five values are set for heat transfer coefficient of external window: $1.0,2.0,3.0,4.0,4.7 \mathrm{~W} / \mathrm{m}^{2} \cdot \mathrm{K}$ and the thermal performance of envelope is set as four groups, as shown in table 1. One-way window simulation analysis, namely, the influence of window-wall ratio of east, west, south and north orientation on energy consumption is simulated respectively. When the window-wall ratio of a certain orientation is taken as variable, the window-wall ratio of other orientations is set as 0 .

Table 1. The values of building envelop thermal performance (unit: $\mathrm{W} / \mathrm{m}^{2} \cdot \mathrm{K}$ )

\begin{tabular}{c|c|c|c|l}
\hline \multicolumn{3}{|c|}{ Building envelope } & \multirow{2}{*}{ Reference standard } \\
\hline wall & roof & window & door & \multicolumn{1}{|l}{} \\
\hline 1.58 & 0.93 & 4.70 & 3.50 & $\begin{array}{l}\text { A. Baseline model of } \\
\text { rural house in severe } \\
\text { cold regions }\end{array}$ \\
\hline 0.50 & 0.45 & 2.20 & 2.00 & $\begin{array}{l}\text { B. Design standard for } \\
\text { energy efficiency of } \\
\text { rural residential } \\
\text { buildings standard for }\end{array}$ \\
\hline 0.30 & 0.25 & 1.80 & 1.50 & $\begin{array}{l}\text { C. Design staren efficiency of } \\
\text { energy } \\
\text { residential buildings in } \\
\text { severe cold and cold } \\
\text { zones }\end{array}$ \\
\hline 0.10 & 0.10 & 1.00 & 1.00 & $\begin{array}{l}\text { D. Technical standard } \\
\text { for nearly zero energy } \\
\text { buildings }\end{array}$ \\
\hline
\end{tabular}

In addition, the rural houses of severe cold regions are mostly detached buildings, exterior windows can be simultaneously arranged in both south and north side. Therefore, a series of conditions are set up to explore the change rule of heating energy consumption under the action of two-way external window. The window-wall ratio also ranges from 0.2 to 0.8 , and the step length is 0.1 .

\section{Results and discussion}

\subsection{One-way window}

Firstly, the variation rule of energy consumption with window-wall ratio is analyzed. As shown in Fig.2, Under A type envelope, energy consumption rises with the increase of window-wall ratio in the east, west and north orientation. When the window-wall ratio reaches 0.5 , the growth rate of energy consumption decreases gradually. However, with the increase of south window-wall ratio, it rises first and then decreases. When the window-wall ratio is 0.5 , the energy consumption reaches the highest. The energy consumption varied the most with the north window-wall ratio among four orientations. Under B and $\mathrm{C}$ type envelope, energy consumption rises with the increase of window-wall ratio in the east and north 
orientation, which having small growth range in the east. When the window-wall ratio reaches 0.4 , the change curve of energy consumption tends to be flat. The energy consumption decreases with the increase of window-wall ratio in the west and south orientation, while the energy consumption decreases with small amplitude in the west. When the window-wall ratio reaches 0.4 , the change curve tends to be horizontal. The energy consumption varied the most with the south window-wall ratio among four orientations. Under D type envelope, the energy consumption rises only with the increase of window-wall ratio in north, but decreases in other orientations.

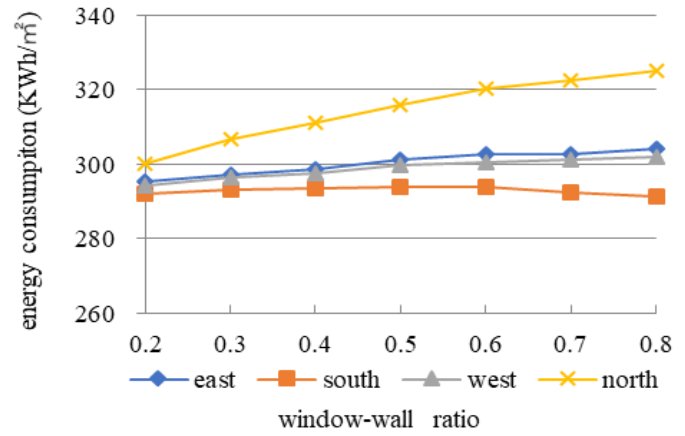

(a) A type

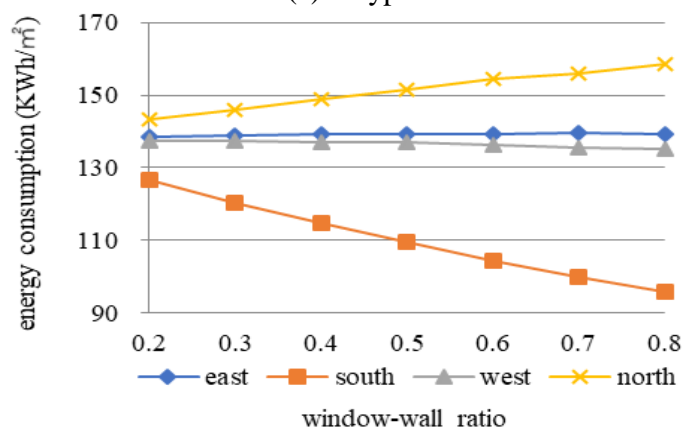

(b) B type

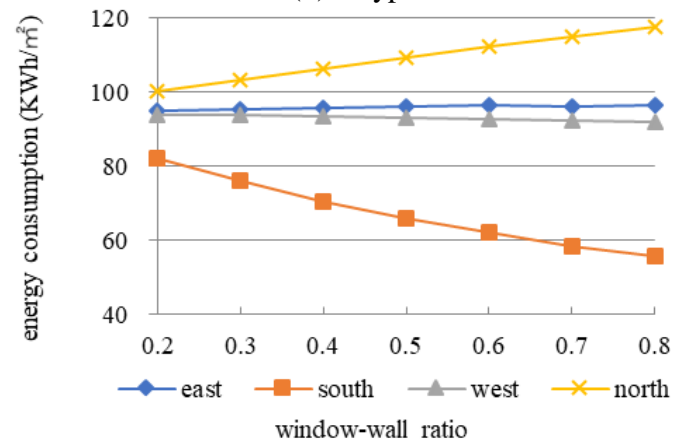

(c) C type

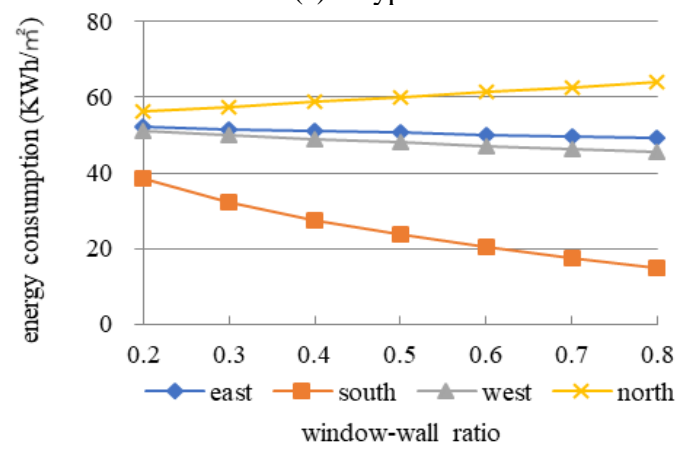

(d) D type

Fig. 2. Energy consumption change curve with window-wall radio under different envelope.
The comprehensive analysis are as follows: (1) The energy consumption rises with the increase of windowwall ratio in north orientation. With the improvement of building envelope's thermal performance, the growth range of energy consumption decreases, but the impact on change rate of energy consumption increases. For example, when the window-wall ratio increases from 0.2 to 0.8 , the energy consumption of $\mathrm{A}$ type envelope increases from 300.27 to $325.26 \mathrm{KWh} / \mathrm{m}^{2}$, increasing by $24.99 \mathrm{KWh} / \mathrm{m}^{2}$, with a growth rate of $8.3 \%$. Regard to D type envelope, the energy consumption increases from 56.19 to $63.97 \mathrm{KWh} / \mathrm{m}^{2}$, increasing by $7.78 \mathrm{KWh} / \mathrm{m}^{2}$, with a growth rate of $13.8 \%$. (2)The variation of energy consumption with the window-wall ratio of east, west and south orientation depends on the building envelope's thermal performance. For the east orientation, when the building envelope's thermal performance is improved to D type, the energy consumption will decrease with the increase of window-wall ratio. For the west orientation, when the building envelope's thermal performance is improved to $\mathrm{B}$ type, the energy consumption will decrease with the increase of window-wall ratio. The change rate of energy consumption in the two orientations is small, indicating that the changes of east and west window-wall ratio of different types envelope have little impact on energy consumption. For the south orientation, only under A type envelope, the energy consumption increases first and then decreases with the increase of window-wall ratio. Under other types of envelope, energy consumption decreases with the increase of window-wall ratio, and with the improvement of building envelope's thermal performance, the reduction range of energy consumption decreases, and the influence on change rate of energy consumption also increases. For example, when the window-wall ratio increases from 0.2 to 0.8 , the energy consumption of B type envelope decreases from 126.66 to $95.92 \mathrm{KWh} / \mathrm{m}^{2}$, decreasing by $30.74 \mathrm{KWh} / \mathrm{m}^{2}$, with a change rate of $24.3 \%$. Regard to D type envelope, the energy consumption decreases from 38.56 to 14.72 $\mathrm{KWh} / \mathrm{m}^{2}$, decreasing by $23.84 \mathrm{KWh} / \mathrm{m}^{2}$, with a change rate of $61.8 \%$.

Secondly, the change rule of energy consumption under the interaction of window-wall ratio and exterior window's $U$ value is analyzed when the building envelope performance (except for windows) is certain. A and D type envelope with large differences in thermal performance are selected for analysis, as shown in Fig.3.

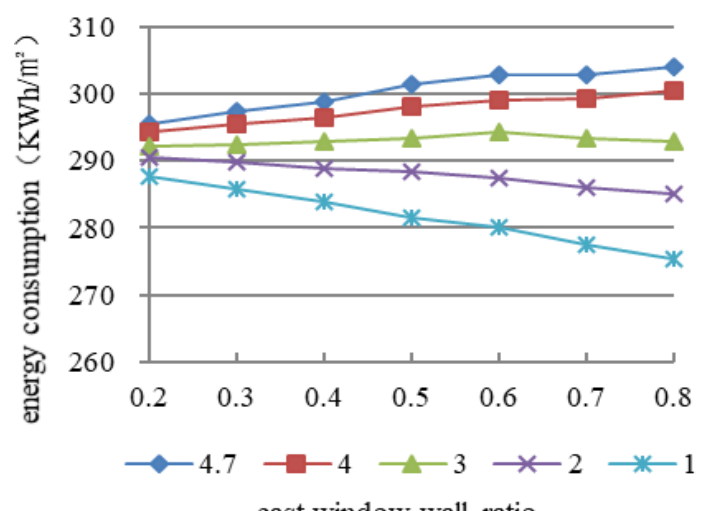

east window-wall ratio 


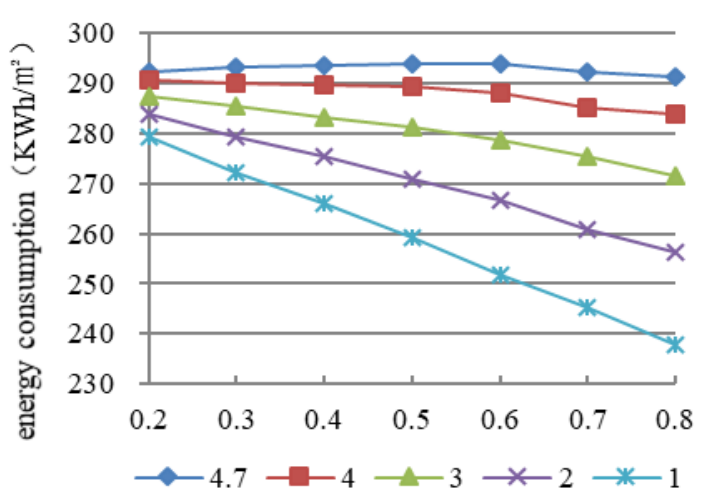

south window-wall ratio

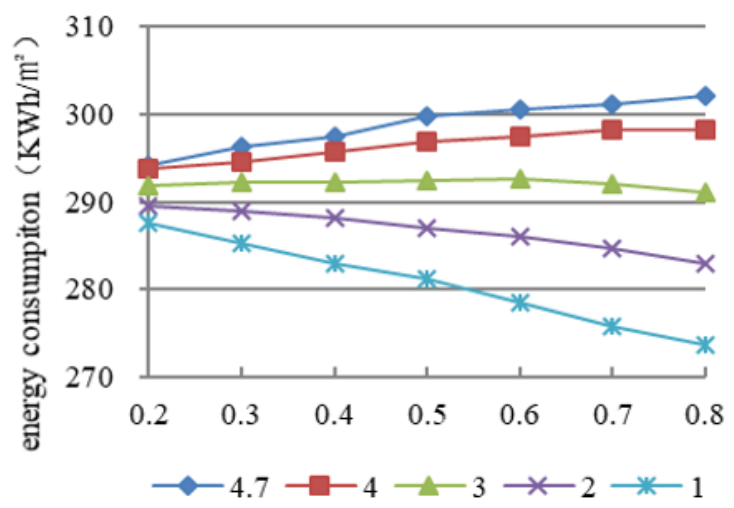

west window-wall ratio

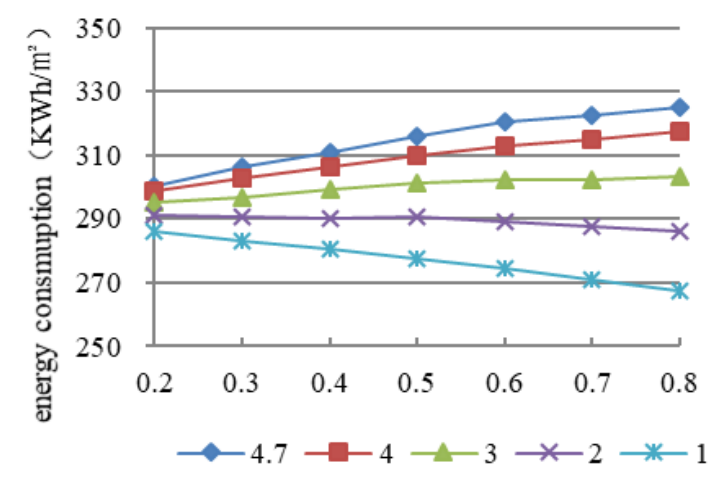

north window-wall ratio

(a) A type

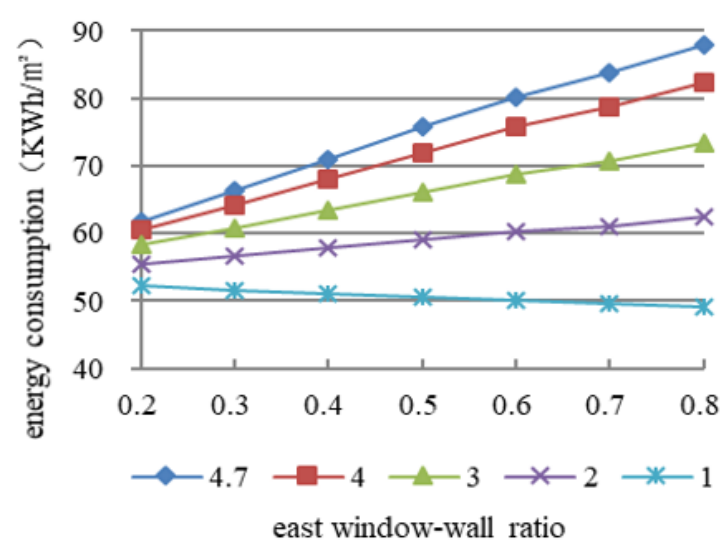

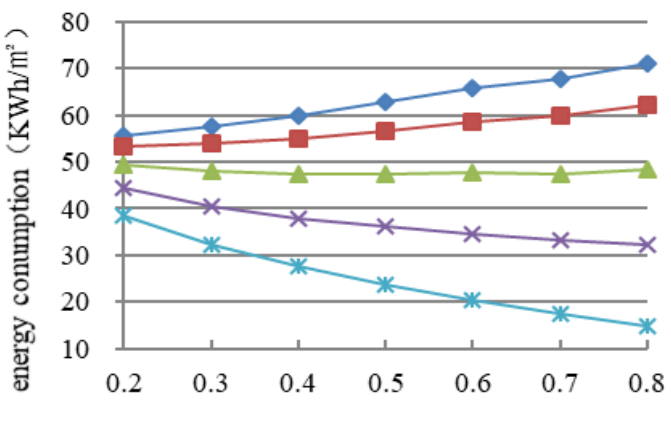

$\multimap-4.7 \rightarrow-4 \multimap-3 \rightarrow 2 \multimap-1$

south window-wall ratio

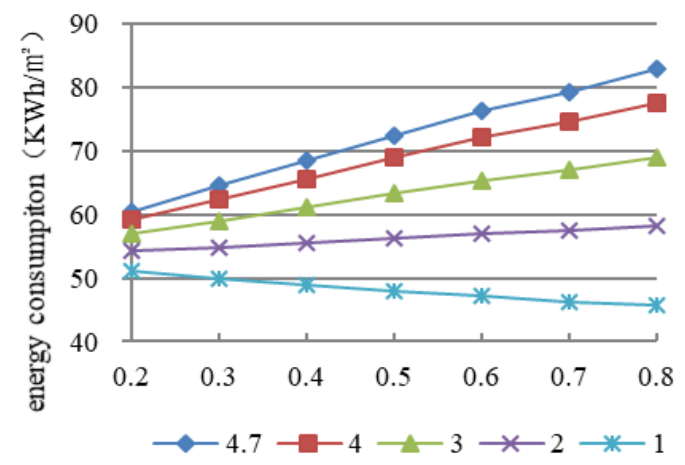

west window-wall ratio

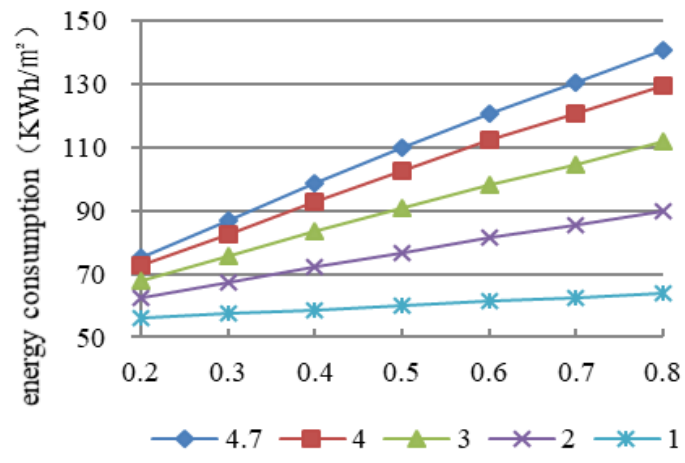

north window-wall ratio

(b) D type

Fig. 3. Energy consumption changing curve with window-wall ratio and window $\mathrm{U}$-value.

The comparative analysis from Fig. 3 are as follows: (1) East window. Under A type envelope, when the Uvalue of exterior window is 4.0 or 4.7 , the energy consumption rises with the increase of window-wall ratio. After the window-wall ratio reaches 0.5 , the change curve tends to be flat. When the U-value is 3.0, the energy consumption increases first and then decreases with the increase of window-wall ratio, but the change range is small. When the $\mathrm{U}$-value increases to 2.0 or 1.0 , the energy consumption decreases linearly with the increase of window-wall ratio. Under D type envelope, when the U-value of exterior window is not less than 2.0, the energy consumption rises linearly with the increase of window-wall ratio, and the higher the Uvalue, the greater the reduction of energy consumption. When the U-value is 1.0, the energy consumption decreases with the increase of window-wall ratio. (2) South window. Under A type envelope, when the Uvalue of exterior window is 4.7 , the energy consumption 
rises first and then decreases with the increase of window-wall ratio. However, as the U-value decreases, the energy consumption decreases with the increase of window-wall ratio, and the changing range gradually increases. For example, when the window-wall ratio increases from 0.2 to 0.8 , the energy consumption decreases by $41.49 \mathrm{KWh} / \mathrm{m}^{2}$ for the U-value of 1.0 , while the energy consumption decreases by 6.94 $\mathrm{KWh} / \mathrm{m}^{2}$ for the U-value of 4.0. Under D type envelope, when the U-value of exterior window is 4.7 or 4.0 , the energy consumption rises with the increase of windowwall ratio. When the U-value is 3.0, the changing curve is flat, indicating that the window-wall ratio has little effect on energy consumption. When the U-value is 2.0 or 1.0 , the energy consumption decreases with the increase of window-wall ratio, and the smaller the Uvalue, the greater the reduction of energy consumption. (3)West window. The change rule of energy consumption is basically consistent with the east orientation. The difference is that the growth rate of energy consumption in east orientation is higher than that in west, while the reduction rate of energy consumption in west orientation is higher than that in east, mainly because of more solar radiation. (4) North window. Under A type envelope, when the $\mathrm{U}$-value of exterior window is not less than 3.0, the energy consumption rises with the increase of window-wall ratio. When the U-value is 2.0 or 1.0 , the energy consumption decreases with the increase of window-wall ratio, mainly because the U-value is close to or higher than the external wall's thermal performance, so increasing the window size will play a certain role in reducing energy consumption. Under D type envelope, the energy consumption rises with the increase of window-wall ratio in all conditions, and with the decrease of window $\mathrm{U}$-value, the negative influence of window-wall ratio on energy saving is reduced.

\subsection{Two-way window}

The change rule of energy consumption under the synergistic action of north and south window is analyzed. As shown in Fig.4, where the X-coordinate is south window-wall ratio and the legend is north window-wall ratio. The variation trend of energy consumption with window-wall ratio is basically consistent under different types of envelope. The difference is that, under A type envelope, when the window-wall ratio increases in north orientation, with the increase of south window-wall ratio, the position of the highest value of energy consumption moves backward. For example, when the north window-wall ratio $\leqslant 0.3$, the maximum energy consumption occurs when the south window-wall ratio is 0.5 . However, when the north window-wall ratio $>0.3$, the maximum energy consumption corresponding to the south window-wall ratio of 0.6 . The change rate of energy consumption depends on building envelope's thermal performance, so the relative value of energy consumption and three-dimensional spatial diagram are used to explore the change rule.

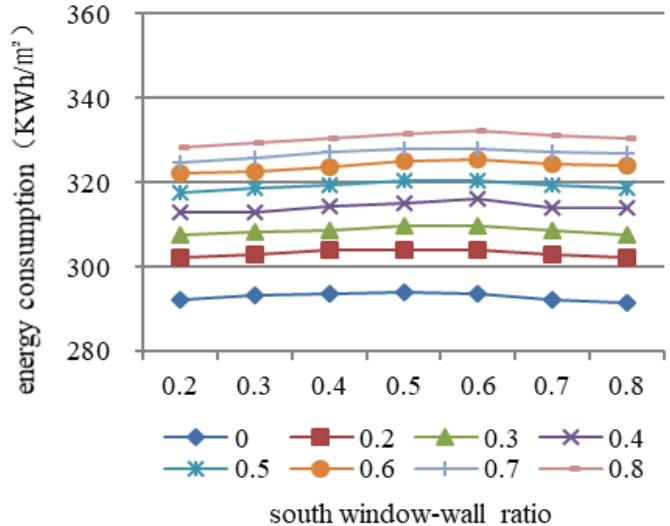

(a) A type

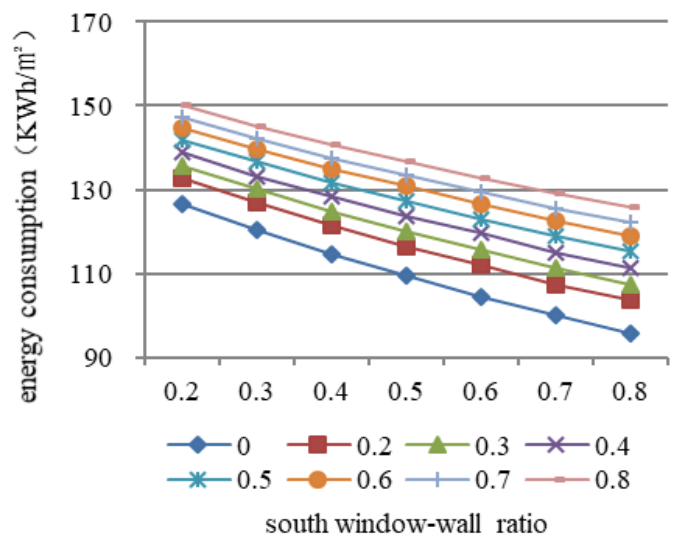

(b) B type

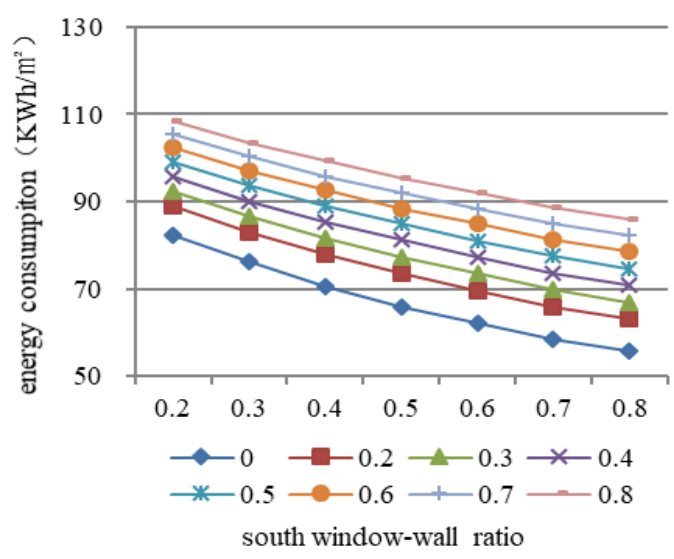

(c) C type

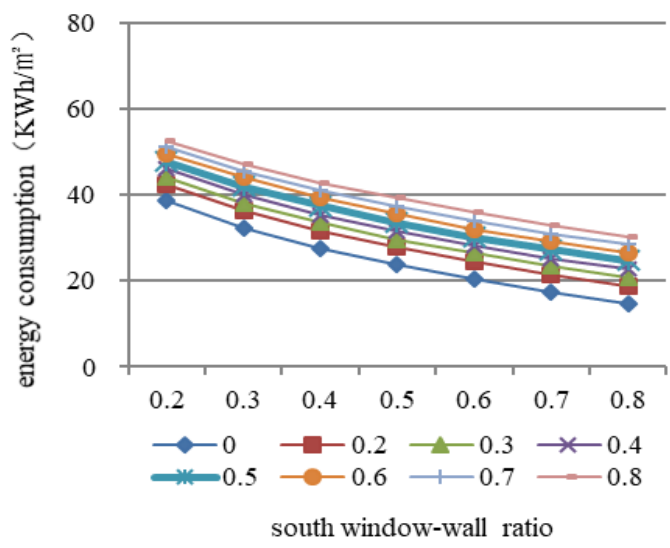

(d) D type

Fig. 4. Energy consumption curve under the synergistic effect of south and north windows. 
Firstly, the variation characteristic of energy consumption with window-wall ratio under the same type envelope is analyzed. As shown in Fig.4 and Fig.5 (a), under A type envelope, when the north window-wall ratio is fixed, the changing of south window-wall ratio has little influence on energy consumption. On the contrary, the changing of north window-wall ratio has a relatively large impact on energy consumption. Under the joint action of two-way window-wall ratio, the threedimensional spatial diagram presents a one-way trend. As shown in Fig.4, under B, C and D types of envelope, the energy consumption has the same changing trend with the two-way window-wall ratio, but the amplitude of variation is different. It can be seen from Fig. 5 (b) that the three-dimensional spatial diagram shows a two-way trend, that is, no matter the window-wall ratio is fixed in south or north orientation, when the window-wall ratio changes in the other orientation, it will have a relatively large impact on energy consumption.

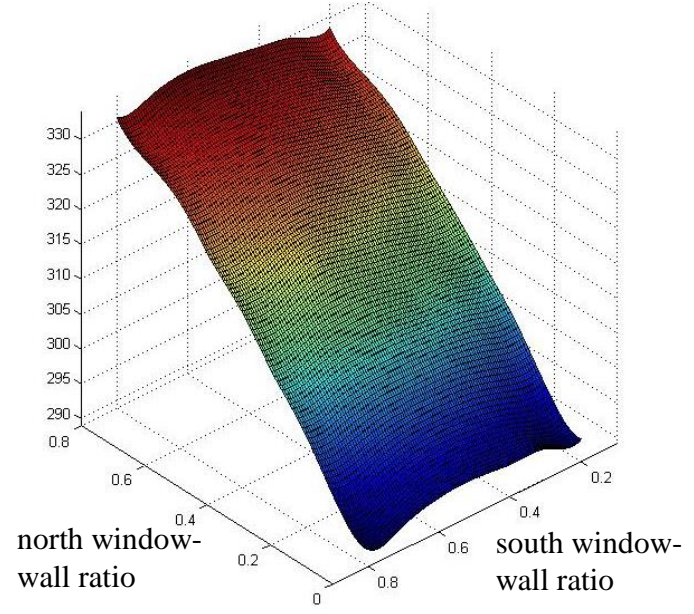

(a) A type

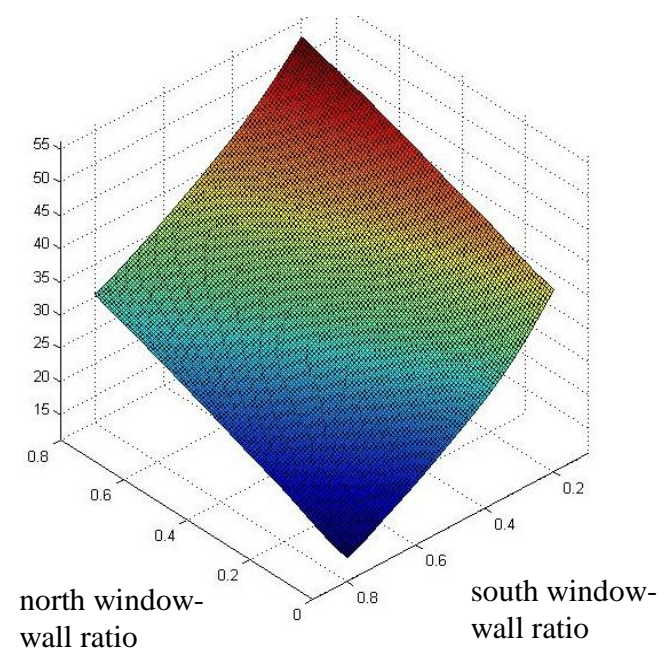

(b) D type

Fig. 5. Three-dimensional changing of energy consumption with double window-wall ratio.

D type envelope is selected as an example to analyze the relative value of energy consumption. The energy consumption is set as 1.0 when the window-wall ratio is 0.2 , and the energy consumption of other window-wall ratio is expressed by relative value. The changing curve is shown in Fig.6.

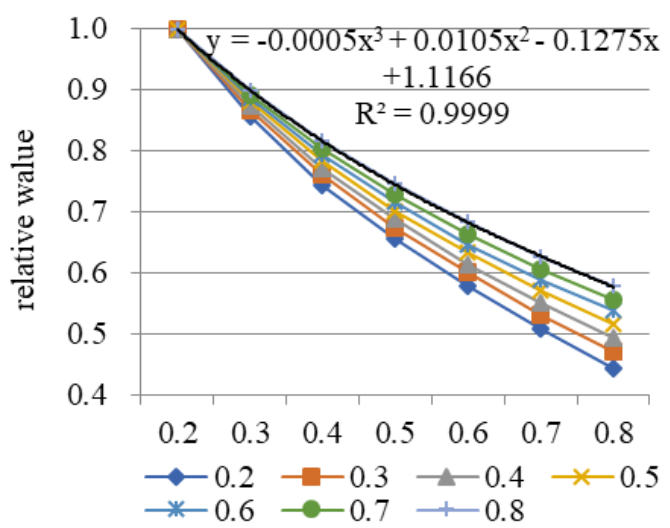

south window-wall ratio

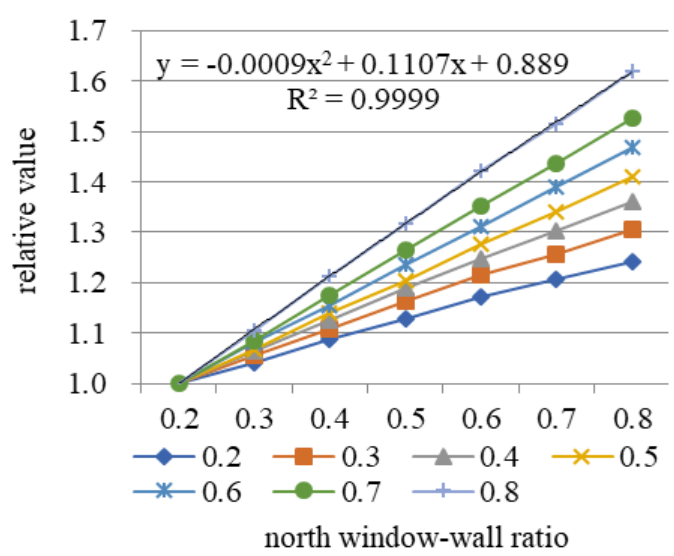

Fig. 6. The changing curve of energy consumption relative value with window-wall ratio.

The comparative analysis from Fig.6 are as follows: (1) With the increase of north window-wall ratio, the difference among relative value of different windowwall ratio in south orientation become smaller. For example, when the north window-wall ratio is 0.2 , the relative value of energy consumption is 0.44 under the south window-wall ratio of 0.8 , and the reduction rate is $56 \%$. However, when the north window-wall ratio is 0.8 , the relative value increases to 0.58 , reducing $42 \%$, indicating that when the north window-wall ratio is larger, the energy saving effect produced by the increase of south window-wall is weakened. (2) With the increase of south window-wall ratio, the difference among relative value of different window-wall ratio in north orientation become larger. For instance, when the south window-wall ratio is 0.2 , the relative value is 1.24 under the north window-wall ratio of 0.8 , and the growth rate is $24 \%$.However, when the south window-wall ratio is 0.8 , the relative value rises to 1.62 , increasing $62 \%$, indicating that when the south window-wall ratio is larger, the adverse effect produced by the increase of north window-wall is enhanced. In a word, the influence of south and north window-wall ratio on energy consumption is mutually restricted. When the larger exterior window needed to be set in the south orientation 
of rural house, the north window-wall ratio should be reduced as much as possible.

Secondly, the variation characteristic of energy consumption with window-wall ratio under different types of envelope is analyzed. Two conditions, the north window-wall ratio of 0.2 and 0.8 , are selected for analysis. As well, the energy consumption is set as 1.0 when the window-wall ratio is 0.2 , and the energy consumption of other window-wall ratio is expressed by relative value, as shown in Fig.7. With the improvement of building envelope's thermal performance, the difference among relative value of different windowwall ratio in south orientation become larger, such as B type envelope, the relative value is 0.84 under the south window-wall ratio of 0.6 , and the reduction rate is $16 \%$, while the relative value decreases to 0.58 under $\mathrm{D}$ type envelope, reducing $42 \%$, indicating that with the higher thermal performance of building envelope, the increase of south window-wall ratio will enhance energy saving rate.

According to the comparison between (a) and (b) in Fig.7, when the north window-wall ratio increases to 0.8 , the energy saving rate decreases with the increase of south window-wall ratio. For example, under D type envelope, the relative value of energy consumption is 0.68 for the south window-wall ratio of 0.6 , and the reduction rate is $32 \%$.

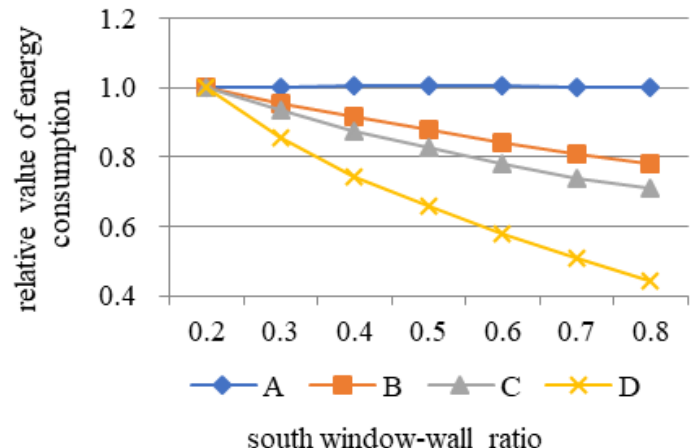

(a) North window-wall ratio of 0.2

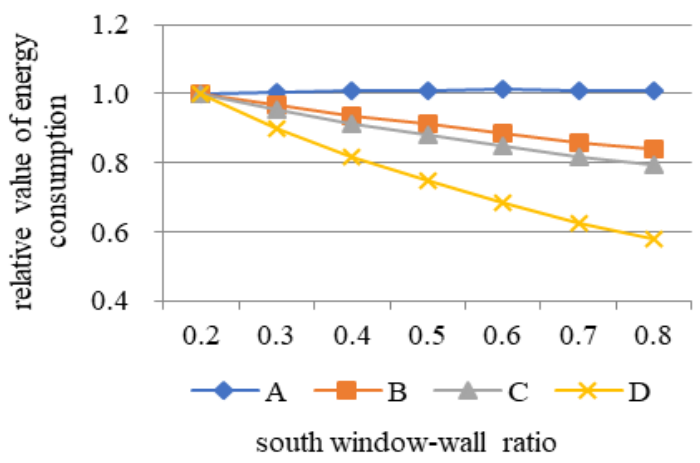

(b) South window-wall ratio of 0.8

Fig. 7. The changing curve of energy consumption relative value with window-wall ratio.

\section{Conclusions}

Through simulation calculation, this paper analyzes the change rule of window-wall ratio on energy consumption under the interaction of building envelope's thermal performance, building orientation and exterior window's U-value. It can be concluded that the changing of east and west window-wall ratio has little influence on energy consumption. The energy consumption rises with the increase of north window-wall ratio, and with the improvement of building envelope's thermal performance the influence on change rate of energy consumption (relative value) increases. For the south window, only under A type envelope, the energy consumption rises first and then decreases with the increase of window-wall ratio. For other types of envelope, the energy consumption decreases with the increase of window-wall ratio, also with the improvement of building envelope's thermal performance the influence on change rate of energy consumption increases.

Regard to the east, west and south window, with the decrease of exterior window's $U$ value, the adverse effect of window-wall ratio increase on energy consumption gradually turns into a favorable trend, but the U-value when the change occurs are different. However, for the north window, when the building envelope's thermal performance reaches a higher standard, even if the U-value of exterior window is improved, its effect on energy consumption is still a growth trend, but the growth range is reduced.

\section{Acknowledgement}

This paper is supported by the National Natural Science Foundation of China (Grant No. 51378136); the Science and Technology Program of Ministry of Housing and Urban-Rural Development of the PRC (Grant No. 2019K-126); the China Postdoctoral Science Foundation (Grant No. 2019M663820) and the Fundamental Research Funds for the Central Universities (Grant No. 3102018xyzzlz002).

\section{References}

1. Ministry of Housing and Urban-Rural Development of the PRC. The $13^{\text {th }}$ Five-Year Plan for Building Energy Conservation and Green Building Development. Supervision Test and Cost of Construction, (1): 1-9 (2017)

2. W. J. Hee, M. A. Alghoul, B. Bakhtyar, et al. The Role of Window Glazing on Daylighting and Energy Saving in Buildings. Renewable \& Sustainable Energy Reviews, 42, 323-343 (2015)

3. H. Liu, Z. Zhang, S. Zhao, et al. The Research about Energy Consumption of Rural Residential Building Influenced by the Window-Wall Ratio in North China. Journal of Hebei University of Engineering (Natural Science Edition), 32(2), 69-72 (2015)

4. B. Yang, Q. Zhang. Optimal Design of Village Residential Envelope Based on eQUEST. Building Energy Efficiency, (5), 67-70 (2015)

5. C. Zhang, M. Liu, Q. Zhang. Performance Analysis of Rural Residences External Window Day Lighting 
in Chongqing Area. Journal of Civil, Architecture \& Environment Engineering, (S1), 198-201 (2013)

6. P. Xue, Q. Li, J. Xie, et al. Optimization of Window-to-Wall Ratio with Sunshades in China Low Latitude Region Considering Daylighting and Energy Saving Requirements. Appl. Energy, 233234, 62-70 (2019)

7. N. Shao, J. Zhang, L. Ma. Analysis on Indoor Thermal Environment and Optimization on Design Parameters of Rural Residence. Journal of Building Engineering, 12, 229-238 (2017)

8. J. Liu, X. Liu, X. Fan, et al. Study on the Optimal Window and Wall Ratio of Village and Town Housing Based on Energy Consumption. IOP Conference Series: Earth and Environmental Science, 219 (2019)

9. Q. Yang, M Liu, C. Shu, et al. Impact Analysis of Window-Wall Ratio on Heating and Cooling Energy
Consumption of Residential Buildings in Hot Summer and Cold Winter Zone in China. Journal of Engineering, 2015, 1-17 (2015)

10. M. S. Lee. Window-to-Wall-Ratio for Energy Reduction in Early Design Stage of Residential Building. Architectural Research, 19 (2017)

11. Y. Huang. Influence of Window-wall Ratio on Energy Consumption of Rural Houses in Cold Regions. Energy and Conservation, (11), 81-82, +96 (2018)

12. ANSI/ASHRAE Standard 140-2004 Building Thermal Envelope and Fabric Load TestsDesignBuilder Version 1.2.0 (2006)

13. China Academy of Building Research et al. Design Standard for Energy Efficiency of Rural Residential Buildings (GB/T 50824) (China Architecture \& Building Press, Beijing, 2012) 